\title{
Robustness of HPHC Reduction for THS 2.2 Aerosol Compared with 3R4F Reference Cigarette Smoke Under High Intensity Puffing Conditions*
}

\author{
by \\ Catherine Goujon, Samuel Kleinhans, Serge Maeder, Laurent Poget, and Jean-Pierre Schaller
}

PMI R\&D, Philip Morris Products S.A., Quai Jeanrenaud 5, CH-2000 Neuchâtel, Switzerland

\section{SUMMARY}

In the absence of standards specific for testing the reduction robustness of the levels of harmful and potentially harmful constituents (HPHCs), the aerosol from the THS 2.2, a heated tobacco product, was compared with the mainstream smoke of the 3R4F reference cigarette over a broad range of machine-smoking regimes. The average reduction and the introduced concept of threshold limits of robust reduction were derived from HPHC concentrations, in mass per tobacco-stick normalized per total puff volume, to propose an alternative for the assessment of products where nicotine-adjusted yields would be inappropriate. In addition, this study explores the influence of 3R4F reference cigarette filter ventilation, and discusses the roles of temperature and precursors in the present context of robustness of HPHC reduction. Fifty-four HPHCs were analyzed under multiple regimes in THS 2.2 aerosol and 3R4F cigarette smoke. The average reduction of HPHC concentrations compared across all regimes characterized the robustness. Threshold limits of reduction of individual HPHCs were statistically determined across all regimes. The results observed under Health Canada Intense (HCI) and more intense regimes indicated that on average the reductions in HPHCs levels investigated in THS 2.2 aerosol were more than $90 \%$ and that the majority of the $54 \mathrm{HPHCs}$ investigated in THS 2.2 aerosol showed more than $90 \%$ reduction. The robustness of THS 2.2 in maintaining the levels of reduction of representative HPHCs, whatever the puffing regime, can be quantified. The mass of HPHC per tobacco-stick normalized per total puff volume is a valuable approach to compare the robustness of the performance of a product over a large range of puffing condi- tions. Our findings will greatly complement the assessment for robustness of current and future similar products where classical approaches would present limitations. [Beitr. Tabakforsch. Int. 29 (2020) 66-83]

\section{KEYWORDS}

Tobacco Heating System, THS 2.2, reduced-risk product, harmful and potentially harmful constituent, HPHC, aerosol chemistry

\section{ZUSAMMENFASSUNG}

In Ermangelung spezifischer Normen zur Überprüfung der Verlässlichkeit der Reduzierung von schädlichen und potenziell schädlichen Bestandteilen (HPHC) wurde das Aerosol von THS 2.2, einem erhitzten Tabakprodukt, mit dem Hauptstromrauch der 3R4F-Referenz-Zigarette über ein breites Spektrum von maschinellen Abrauchbedingungen verglichen. Um die mit einer Normalisierung auf Nikotin einhergehenden Limitierungen zu umgehen, wurden für die Berechnung der durchschnittlichen Reduzierung der HPHC-Gehalte sowie für das vorgestellte Konzept der Schwellengrenzwerte, die gefundenen HPHC Gehalte pro Tabakprodukt auf das Gesamtzugvolumen bezogen. Darüber hinaus wurde der Einfluss der Ventilation der 3R4F-Referenz-Zigarette auf die Stabilität der HPHCReduzierung untersucht und die Rolle von Temperatur und HPHC-Präkursor diskutiert. Für die Studie wurden THS 2.2-Aerosol und 3R4F-Zigarettenrauch mit verschiedenen Abrauchbedingungen generiert und 54 HPHCs 
analysiert. Die durchschnittliche Reduzierung der HPHCKonzentrationen über alle angewendeten Abrauchbedingungen stellt eine verlässliche Beschreibung deren Reduzierung dar. Die minimale Reduzierung der einzelnen HPHCs wurde statistisch über alle Abrauchbedingungen hinweg ermittelt. Die unter HCI- und intensiveren Abrauchbedingungen beobachteten Ergebnisse zeigten eine durchschnittliche Reduzierung der HPHC Gehalte im THS 2.2-Aerosol von mehr als 90\% im Vergleich zu 3R4FZigarettenrauch. Weiterhin wurde eine Reduzierung von mehr als $90 \%$ bei einer Mehrheit der untersuchten 54 HPHCs festgestellt. Die Robustheit von THS 2.2 bei der Aufrechterhaltung der Reduzierungsniveaus repräsentativer HPHCs kann, unabhängig vom Rauchregime, quantifiziert werden. Die Normalisierung der HPHC Gehalte pro Tabakprodukt auf das Gesamtzugvolumen stellt einen wertvollen Ansatz dar, um die Zuverlässigkeit eines Produktes über einen weiten Bereich von Zugbedingungen $\mathrm{zu}$ überprüfen - insbesondere in Hinblick auf die nicht aussagekräftige Normalisierung auf Nikotin. Unsere Ergebnisse werden die Bewertung der Zuverlässigkeit aktueller und zukünftiger ähnlicher Produkte, bei denen klassische Ansätze an ihre Grenzen stossen, erheblich ergänzen. [Beitr. Tabakforsch. Int. 29 (2020) 66-83]

\section{RESUME}

A défaut de normes spécifiques à l'évaluation de la robustesse de la réduction des niveaux de composées nocifs et potentiellement nocifs (HPHC en anglais), l'aérosol généré par le THS 2.2, un produit à partir de tabac chauffé, a été comparé avec la fumée principale d'une cigarette de référence 3R4F, en considérant une large variété de régimes de bouffées réalisée à partir de machines à fumer analytiques. La réduction moyenne ainsi que le concept introduit de seuil limite de robustesse des réductions mesurées ont été dérivés de la concentration en masse de HPHC exprimée par stick de tabac et normalisée par le volume total de bouffée, ceci afin de proposer une alternative pour l'évaluation de certains produits, lorsqu'un ajustement des taux par rapport à la nicotine ne serait pas applicable. Par ailleurs, cette étude explore l'influence de la ventilation de la cigarette de référence $3 \mathrm{R} 4 \mathrm{~F}$ et la discussion aborde le rôle de la température et des précurseurs de composés formés dans le contexte de la robustesse de réduction des niveaux de HPHCs. 54 HPHCs ont été analysés, sous de multiples régimes, dans l'aérosol produit par THS 2.2 et dans la fumée principale de la cigarette $3 \mathrm{R} 4 \mathrm{~F}$. La robustesse a été déterminée par la comparaison des combinaisons croisées de réduction moyenne des HPHCs entre tous les régimes. Des valeurs seuils de robustesse propre à chaque HPHC ont été statistiquement calculées pour l'ensemble des régimes. Les résultats observés dans les conditions "Health Canada Intense" (HCI) ainsi qu'à des régimes plus intenses ont indiqué, qu'en moyenne, la réduction des niveaux des HPHCs était supérieure à $90 \%$ et que la majorité des 54 HPHCs étudiés dans l'aérosol THS 2.2 présentait même un taux de réduction supérieur à $90 \%$. La robustesse du THS 2.2 dans le maintien des niveaux de réduction des HPHCs considérés peut être quantifiée, quel que soit le régime suivi. Le fait de normaliser la masse
d'HPHC par stick de tabac et par le volume total de bouffée est une manière adaptée de comparer la robustesse de la performance mesurée d'un produit au travers d'une vaste palette de régimes de bouffées. Nos observations vont considérablement contribuer aux études de robustesse des produits courants et futurs dans le cas où une approche classique n'est pas applicable. [Beitr. Tabakforsch. Int. 29 (2020) 66-83]

\section{INTRODUCTION}

The recent emergence and rapid growth in the numbers of products designed to offer safer alternatives for adult smokers who cannot, or do not wish to, stop smoking, requires a concomitant science-based, due diligent assessment.

Evaluating the chemical properties of a product's aerosol is a key step for assessing and substantiating the potential for lowering the user's exposure to harmful and potentially harmful constituents (HPHCs). In this investigation, the composition of the aerosol generated by the Tobacco Heating System 2.2 (THS 2.2), a heated tobacco product developed by Philip Morris Products S.A. and commercialized under the brand name IQOS, has been compared with the composition of cigarette smoke over a broad range of machine-smoking regimes. A normalized approach was used, allowing cross-comparison of multiple regimes to determine the reduction of HPHC levels between THS 2.2 aerosol and cigarette smoke, the latter represented by the 3R4F reference cigarette (University of Kentucky, Kentucky Tobacco Research and Development Center). Unlike cigarettes, THS 2.2 uses a precisely controlled heating device into which a specially designed tobacco product, the tobacco-stick, is inserted and heated to generate an aerosol. The adjustment of machine-smoked HPHC yields in relation to nicotine yield (nicotine-adjusted yield, expressed as HPHC yield per milligram of nicotine) is commonly used to express the level of toxicants to which cigarette smokers would be exposed (1-2). Reporting THS 2.2 HPHC deliveries as nicotine-adjusted yields is a suitable approach for comparing products with similar nicotine content, however, the levels of nicotine delivered by products designed as alternatives to smoking may be very different. For example, electronic cigarettes may use e-liquids containing from zero to several percent nicotine. It is also interesting to mention the authorization of new tobacco products (e.g., FDA press release on December 17, 2019), which are combustible, filtered cigarettes that contain a reduced amount of nicotine compared to typical commercial cigarettes. Therefore, reporting HPHC yields normalized by total puff volume was considered as an alternative normalization approach, relevant for situations where nicotine-adjusted yields would be considered as providing an inaccurate comparison between different products, particularly if the comparisons were conducted over a broad range of machine-smoking conditions. Although comparative assessments are still often reported on a nicotine-adjusted basis to accommodate different reporting requirements, it is important to mention that yields on a nicotine-adjusted basis would not necessarily account for any compensatory behavior (either to obtain more nicotine 
from lower concentration liquids or less nicotine from higher concentration liquids). For instance, the study of compensatory behavior conducted with experienced e-cigarette users, was found to be partially effective (3) or unclear (4).

The proposed normalization approaches for the assessment of robustness for HPHC reduction included the transformation of HPHC yields into aerosol/smoke HPHC concentrations, and the representation of HPHC yields in relation to the observed nicotine yields. The concept for the use of aerosol/smoke concentrations is based on the arithmetical division of the HPHC yields by the total amount of aerosol generated, as described by BELUSHKIN et al. (5) addressing the role of testing standards in smoke-free product assessments. The latter approach would be entirely appropriate for comparing a product containing no nicotine with a nicotine-containing product, whereby HPHC yields are normalized in accordance with the total volume of aerosol delivered, and not with the amount of nicotine delivered. By using volume-adjusted concentrations to detect changes in product performance, BELUSHKIN et al. have introduced an interesting approach to evaluate and compare emissions robustness for different product categories, subjected to a broad range of puffing intensities.

The aim of the present study was to characterize robustness by evaluating HPHC reduction consistency over multiple regimes, firstly by comparing relative reductions using the average for all investigated HPHCs, and secondly by determining the levels of reduction for each HPHC individually, with respect to predefined 'robustness' limits. The intention was to characterize the performance of THS 2.2 for reducing the levels of HPHCs, with a focus on puffing intensities that exceeded the intensity of the Health Canada intense (HCI) regime. It is important to understand that the volume-adjusted approach is meaningful only when used to assess products in accordance with their intended mode of operation and possible usage conditions. For instance, by design, each tobacco stick can be used in THS 2.2 for a maximum of $6 \mathrm{~min}$, or for a maximum of 14 puffs, whichever comes first. Testing the product for longer than $6 \mathrm{~min}$, or taking more than 14 puffs, would be incorrect and would adversely influence the determination of volume-adjusted HPHC concentrations. Most important, the objective of this study was not to determine the absolute performance for the reduction of HPHC levels in THS 2.2 aerosol compared to $3 \mathrm{R} 4 \mathrm{~F}$ smoke. Instead, the aim was to characterize the robustness of these reductions in HPHC concentrations, compared to cigarette smoke, when using THS 2.2 over a range of high intensity puffing regimes. In addition, considering the novelty of the approach, multiple smoking regimes were also applied for the $3 \mathrm{R} 4 \mathrm{~F}$ reference cigarette, in order to verify the influence of smoking regime upon volume-adjusted HPHC concentrations for cigarettes. Considering the influence of puff volume and filter ventilation on constituents yields measured in mainstream cigarette smoke (6), the possible lack of robustness for volumeadjusted HPHC yields in 3R4F smoke required a careful consideration when determining the robustness for HPHC reductions in THS 2.2 aerosol.

\section{EXPERIMENTAL PROCEDURES}

\section{Reference cigarette}

The reference cigarette used was 3R4F, supplied by the University of Kentucky (University of Kentucky Center for Tobacco Reference products, Lexington, KY, USA; http://www.ca.uky.edu/refcig/).

\section{THS 2.2 tobacco-sticks}

Commercially produced non-mentholated (regular) tobacco-sticks, known as HeatSticks or HEETS, designed for use with the THS 2.2 device were used. Published studies (7-8) describe in detail the design and functionality principles for THS 2.2.

\section{Aerosol/smoke generation and analysis}

In one published study (9) an established list of principal aerosol/smoke constituents and 54 relevant HPHCs was used to assess the levels in THS 2.2 aerosol, compared to the mainstream smoke of the $3 \mathrm{R} 4 \mathrm{~F}$ reference cigarette. The same list of 54 relevant HPHCs (Supplementary information Table S 1) was considered in the present study.

The HCI regime is the machine-smoking regime commonly used as a reference, which was designed to generate emissions under a more intensive set of smoking parameters that would provide a 'maximum' exposure limit that could be exceeded by very few smokers. However it is widely recognized that even such an 'intensive' regime does not adequately represent the extremes relevant for human smoking behavior. Without specific standards and recommendations for testing robustness, alternative puffing regimes used to generate THS 2.2 aerosol were selected based on human puffing conditions observed with users (7), including an extreme regime representing very high-end usage conditions ( $110 \mathrm{~mL}$ puff volume, $4.5 \mathrm{~s}$ puff duration, $22 \mathrm{~s}$ puff interval). The most extreme regime used to generate $3 \mathrm{R} 4 \mathrm{~F}$ mainstream smoke $(80 \mathrm{~mL}$ puff volume, $2.4 \mathrm{~s}$ puff duration, $25 \mathrm{~s}$ puff interval) was selected to exceed alternative high-end regimes used in previously reported cigarette studies (10-11).

The HCI standard requires $100 \%$ occlusion of cigarette filter ventilation. For this investigation, both $100 \%$ and $50 \%$ occlusion of $3 \mathrm{R} 4 \mathrm{~F}$ filter ventilation was applied for each regime used, to evaluate the influence of this parameter on the robustness for HPHC reduction. Blocking ventilation was out of context for THS 2.2 because the tobacco-stick is designed without ventilation.

The analyses were performed at Labstat International ULC (Kitchener, Ontario, Canada), an ISO/IEC 17025:2005 (12) laboratory accredited for all the mandated tobacco-related Health Canada methods (13). The cigarettes and tobaccosticks were conditioned according to ISO 3402:1999 (14). The test methods and method modifications for the analysis of THS 2.2 aerosol and 3R4F mainstream tobacco smoke are referenced in Supplementary information Table S 1 and were applied as described therein.

Five replicates were used for the analyses, unless specified otherwise. 
Generation of THS 2.2 aerosol using multiple machinesmoking regimes

Five different regimes described in Table 1were used to generate THS 2.2 aerosol: augmented regime (A), extreme regime $(\mathrm{E})$, high regime $(\mathrm{H})$, intense regime $(\mathrm{N})$ and low regime (L). These arbitrary names were defined for the identification of standard and non-standard regimes used for the aerosol generation of THS 2.2. Regimes L and N applied to THS 2.2 were representative of the puffing conditions for the ISO (ISO) and Canada Intense (HCI) standards, respectively. The THS 2.2 system is programmed to finish heating after a maximum period of $6 \mathrm{~min}$ or after 14 puffs, whichever comes first. Accordingly, the puff intervals applied for the ISO (60 s) and HCI regimes $(30 \mathrm{~s})$ resulted in the generation of 6 puffs and 12 puffs, respectively.

Generation of mainstream smoke of $3 R 4 F$ using multiple machine-smoking regimes and two levels of filter ventilation occlusion

Three different regimes described in Table 2 were used to generate 3R4F mainstream smoke. For each regime, 3R4F reference cigarettes were smoked with $50 \%$ and $100 \%$ ventilation occlusion, achieved by applying adhesive tape strips. Irrespective of the level of ventilation occlusion, the low regime $(\mathrm{L})$ and the intense regime $(\mathrm{N})$ represent puffing conditions for the ISO (ISO) and Health Canada Intense (HCI) standard regimes, respectively.

\section{Calculation of aerosol/smoke concentration}

The HPHC aerosol/smoke concentrations were calculated as mass per tobacco-stick normalized per total puff volume for each product, constituent, regime and replicate. The number of puffs multiplied by the volume of puffs determined the total puff volume. The number of puffs averaged between all items of a replicate was used for the 3R4F cigarette and the number of puffs predefined by the regime was used for the THS 2.2. These data were used for the entire evaluation process as described below. The mean and standard deviation of yields and volume-adjusted yields are reported in Table 6 and Table 7, respectively.

\section{Calculation of nicotine-adjusted yields}

Nicotine-adjusted HPHC yields were calculated as mass per tobacco-stick normalized for the corresponding nicotine yield for each product, constituent, regime and replicate. These data were used for the calculation of average reductions for THS 2.2 versus 3R4F per regime, using data for all HPHCs combined. The mean and standard deviation of nicotine-adjusted yields are reported in Table 8 .

\section{Data evaluation}

Descriptive statistics per product and machine-smoking condition were computed for all HPHCs investigated in this study.

The relative reduction was defined as the reduction of the HPHC concentration in THS 2.2 aerosol compared with
Table 1. Machine-smoking parameters used for the generation of THS 2.2 aerosol

\begin{tabular}{l|r|r|r|r|r}
\hline \multirow{2}{*}{ Parameter (Unit) } & \multicolumn{5}{|c}{ Regime } \\
\cline { 2 - 6 } & $\begin{array}{c}\text { Low } \\
\text { L(ISO) }\end{array}$ & $\begin{array}{c}\text { Normal } \\
\mathrm{N}(\mathrm{HCl})\end{array}$ & $\begin{array}{c}\text { Augmented } \\
\mathrm{A}\end{array}$ & $\begin{array}{c}\text { High } \\
\mathrm{H}\end{array}$ & $\begin{array}{c}\text { Extreme } \\
\mathrm{E}\end{array}$ \\
\hline Puff volume (mL) & 35 & 55 & 60 & 80 & 110 \\
Puff interval (s) & 60 & 30 & 25 & 25 & 22 \\
Puff duration (s) & 2.0 & 2.0 & 2.4 & 2.4 & 4.5 \\
Puff number (n) & 6 & 12 & 14 & 14 & 14 \\
\hline
\end{tabular}

Table 2. Machine-smoking parameters used for generation of 3R4F mainstream smoke

\begin{tabular}{l|r|r|r|r|r|r}
\hline \multirow{2}{*}{ Parameter (Unit) } & \multicolumn{7}{|c}{ Regime } \\
\cline { 2 - 7 } & $\mathrm{L}(50)$ & $\mathrm{L}(100)$ & $\mathrm{N}(50)$ & $\mathrm{N}(100)$ & $\mathrm{H}(50)$ & $\mathrm{H}(100)$ \\
\hline Puff volume (mL) & 35 & 35 & 55 & 55 & 80 & 80 \\
Puff interval (s) & 60 & 60 & 30 & 30 & 25 & 25 \\
Puff duration (s) & 2.0 & 2.0 & 2.0 & 2.0 & 2.0 & 2.4 \\
Occlusion (\%) & 50 & 100 & 50 & 100 & 50 & 100
\end{tabular}

that in 3R4F cigarette smoke.

Statistical analysis Bayesian ANOVA (15-16) was performed to assess the reduction of HPHCs across the different machine-smoking conditions. The mean concentrations and respective 0.95 confidence intervals for each HPHC were calculated for each of the five conditions tested for 3R4F and each of the six conditions tested for THS 2.2. Relative reductions for the levels of individual HPHCs and their respective 0.95 confidence intervals were calculated for the 30 combinations of conditions using Markov Chains produced by the Bayesian model $(15,17)$. For each of the 30 combinations, the average reductions were calculated for both nicotine-adjusted and volume-normalized yields using combined data from all the HPHCs measured.

Pre-defined standard distributions, i.e. non-informative priors, were assigned to all Bayesian model parameters to match the classical frequentist modelling results. The Bayesian approach allowed the computation of uncertainty around complex statistical estimates.

SAS Enterprise Guide 7.1 was used for the statistical treatments, including Procedures MCMC and MIXED (18-19) for the computation aspects.

\section{Calculation of relative reduction including determination limits}

Aerosol and smoke constituent values were estimated when they were below the limit of detection (LOD) and/or lower limit of quantitation (LOQ) of the analytical method. For the THS 2.2, the values used to calculate the relative reduction between THS 2.2 and 3R4F were imputed as follows: for results $<\mathrm{LOD}$, the value was estimated by the LOD; for results $<$ LOQ but $>$ LOD, the value was estimated by the LOQ.

When more than two out of five replicate values used in the calculation of reduction were below the LOQ, the 0.95 confidence intervals were not reported. The number of acceptable values below the LOQ were considered individually in THS 2.2 and 3R4F emissions. 
No HPHC reduction was reported for conditions presenting more than two out of five replicate values for $3 \mathrm{R} 4 \mathrm{~F}$ reference cigarette emissions below the LOQ.

\section{Threshold limit of robust reduction}

Each HPHC was categorized to one of 11 individual threshold limits of robust reduction. The first threshold limit category was established for cases demonstrating a minimum of $50 \%$ reduction, and the next successive limits follow a progression using 5\% increments until the last threshold limit being fixed at $99 \%$.

The acceptance criteria in a category is the non-inferiority of the lower band of the 0.95 confidence interval of the HPHC reduction with the respective threshold limit. The test is unilateral and can detect non-inferiority with at least 0.975 probability. For each investigated HPHC, the highest threshold limit demonstrating non-inferiority of reduction for all regimes served to determine the threshold limit of robust reduction.

\section{RESULTS}

The dataset of smoke/aerosol constituent yields is available in Supplementary information Table S 2. Descriptive statistics for the concentrations of investigated constituents generated in THS 2.2 aerosol and 3R4F cigarette mainstream smoke are compiled in Supplementary information Table S 3 and Supplementary information Table S 4, respectively. These tables summarize the results for 57 analytes, including nicotine, glycerol, NFDPM and 54 HPHCs for all tested conditions.

The relative reductions of HPHC concentrations in THS 2.2 aerosol were calculated as a percentage of the concentration in 3R4F cigarette mainstream smoke. Out of 54 investigated HPHCs, 15 presented various proportions of determined values falling below the LOQ, and 13 caused computational limitations due to the preponderance of values below the LOQ. Supplementary information Table $\mathrm{S} 5$ presents the imputed compounds and the proportions of cases per product. For nine HPHCs, the preponderance of imputed values resulted in computational optimization shortage, such that the 0.95 confidence intervals of reduction were not calculated. Instead, the results reported in Supplementary information Table S 6 for these nine compounds (2-aminonaphtalene, arsenic, cadmium, crotonaldehyde, dibenz $[a, h]$ anthracene, lead, quinoline, resorcinol and vinyl chloride) are the minimum and maximum reduction means observed over the combinations of regimes for the two separated groups of 3R4F filter ventilation occlusion. Since more than $90 \%$ of the values were below LOQ for both THS 2.2 and the 3R4F cigarette, the calculation of reduction was not applicable for chromium, nickel, nitrobenzene and selenium. Excluding these four HPHCs, the average reductions of HPHC concentrations were calculated across all smoking-machine regimes used to generate THS 2.2 aerosol and 3R4F smoke. For arsenic, dibenz $[a, h]-$ anthracene, lead and resorcinol, no reductions were calculated for conditions including more than two out of five 3R4F replicates with values falling below the LOQ. As a consequence, the number of HPHCs used in the calculation

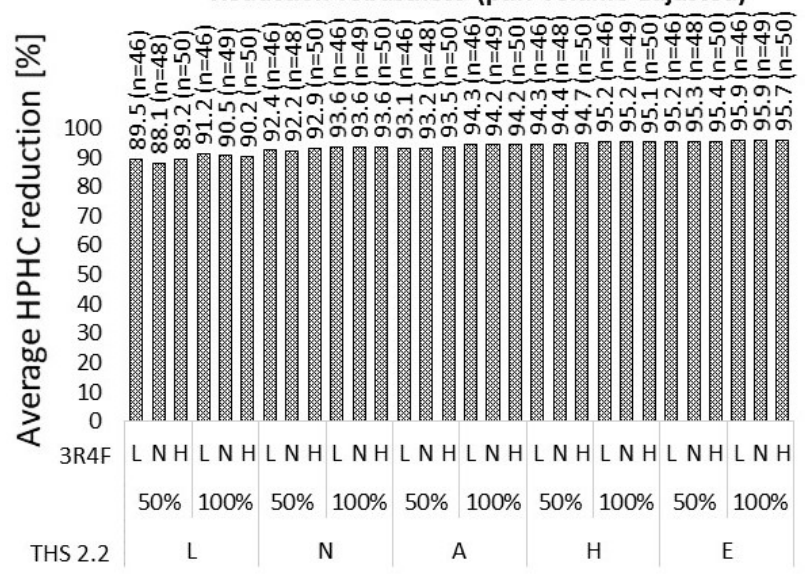

Figure 1. Average reduction of HPHC concentrations (puff volume adjusted yields) in THS 2.2 aerosol as a percentage of concentration in $3 \mathrm{R} 4 \mathrm{~F}$ cigarette mainstream smoke. Comparison between various combinations of regimes and two levels of filter ventilation occlusion for $3 \mathrm{R} 4 \mathrm{~F}$ (i.e., $50 \%$ and $100 \%$ ). The respective puffing conditions identified by $\mathrm{A}, \mathrm{E}, \mathrm{H}, \mathrm{L}$ and $\mathrm{N}$ are described in Table 1 and Table 2. The number of HPHCs (n) considered for the calculation of the average reductions varied between the different combinations of conditions.

Reduction robustness (nicotine-adjusted)

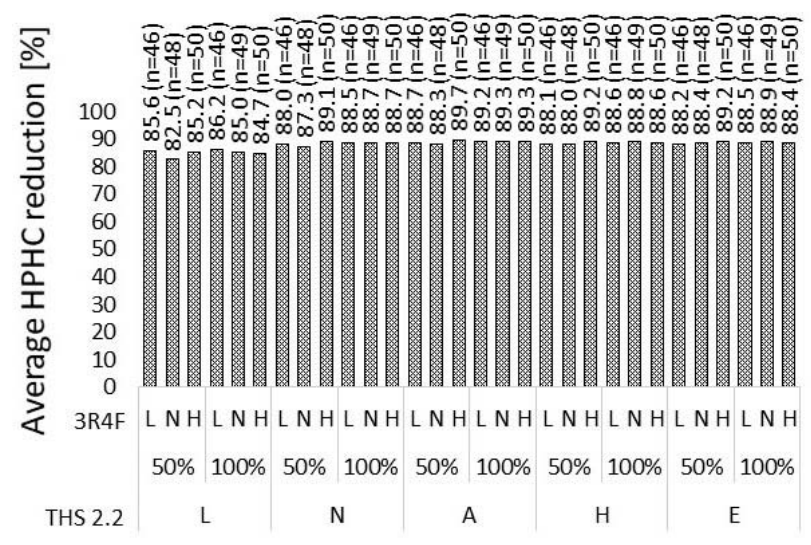

Figure 2. Average reduction of nicotine adjusted HPHC yields in THS 2.2 aerosol as a percentage of concentration in 3R4F cigarette mainstream smoke. Comparison between various combinations of regimes and two levels of filter ventilation occlusion for $3 \mathrm{R} 4 \mathrm{~F}$ (i.e., $50 \%$ and $100 \%$ ). The respective puffing conditions identified by A, E, H, L and $\mathrm{N}$ are described in Table 1 and Table 2 . The number of HPHCs ( $n$ ) considered for the calculation of the average reductions varied between the different combinations of conditions.

of the average reductions changed between conditions (ranging between 46 and 50). Figure 1 summarizes the average HPHC reductions calculated for each regime combination based upon puff volume-adjusted yields (range $88.1 \%$ to $95.9 \%$ ). Figure 2 summarizes the average HPHC reductions calculated for each regime combination based upon nicotine-adjusted yields (range $82.5 \%$ to $89.7 \%$ ).

For aerosol generated by THS 2.2 under the HCI regime $(\mathrm{N})$, the average reduction in puff volume-adjusted HPHC concentrations relative to $3 \mathrm{R} 4 \mathrm{~F}$ was in the range $92.2 \%$ to $93.6 \%$ comparing all the regimes used for the $3 \mathrm{R} 4 \mathrm{~F}$ cigarette $(87.3 \%$ to $89.1 \%$ using nicotine-adjusted data). 
Applying more intense regimes than HCI to THS 2.2 (A, H and $\mathrm{E}$ ), average reductions in the range from $93.1 \%$ to 95.9\% were observed using puff volume-adjusted HPHC concentrations relative to $3 \mathrm{R} 4 \mathrm{~F}$ ( $88.1 \%$ to $89.7 \%$ using nicotine-adjusted data), irrespective of the smoking regime used for 3R4F. The puff volume-adjusted reductions for THS 2.2 under ISO conditions (L) were in the range $90.2 \%$ to $91.2 \%$ (84.7\% to $86.2 \%$ using nicotine-adjusted data) when compared with 3R4F cigarette smoked with $100 \%$ occlusion of filter ventilation, and $88.1 \%$ to $89.5 \%(82.5 \%$ to $85.6 \%$ using nicotine-adjusted data) with $50 \%$ occlusion of filter ventilation. The influence of the cigarette filter ventilation has already been reported in a previous study comparing the ratio of emission concentrations between the $\mathrm{HCI}$ and the ISO machine-smoking regimes (5).

The poorest reduction performance achieved for individual HPHCs across all puffing regimes was used to define the threshold limit for robust reduction. For a first group of conditions, 3R4F cigarettes smoked with $100 \%$ occlusion of filter ventilation were used to calculate the relative reduction of HPHC concentrations in THS 2.2 aerosol. The 0.95 confidence intervals for reductions, calculated across all regimes, are reported in Supplementary information Table S 7.

Table 3 presents a summary of the threshold limit of robust reductions resulting from non-inferiority tests conducted over all the regimes where HPHC reductions were calculated with $3 \mathrm{R} 4 \mathrm{~F}$ cigarettes smoked with 100\% occlusion of filter ventilation.

Studies conducted in the framework of the reduced exposure assessment of THS 2.2 (20-21) support the continued use of the HCI regime as it became apparent that the ISO smoking regime only represented the low end of THS 2.2 usage. Therefore, the calculation of threshold limits for robust reduction was repeated excluding data from the ISO regime (c.f. summary in Table 4), the intention being to characterize THS 2.2 reduction robustness under puffing intensities at and beyond the HCI regime.

For a second group of conditions, Supplementary Information Table $\mathrm{S} 8$ reports the 0.95 confidence intervals of reduction referring to $3 \mathrm{R} 4 \mathrm{~F}$ cigarette smoked with $50 \%$ occlusion of filter ventilation.

Table 5 presents a summary of the threshold limit of robust reductions resulting from non-inferiority tests conducted over all the regimes where HPHC reductions were calculated with 3R4F cigarettes smoked with 50\% occlusion of filter ventilation excluding the ISO regime.

The change from total to partial filter ventilation affected the concentration of some HPHCs in cigarette smoke. The bar charts in Figure 3 are examples showing the change in $\mathrm{HPHC}$ concentrations between products and conditions and the levels of reduction calculated from the combinations of these factors. When comparing the same puffing intensities, the influence of filter ventilation is clear on pyridine, showing higher concentrations with $100 \%$ occlusion of 3R4F filter ventilation, and on phenol showing the inverse effect. The charts also show the apparent differences of evolution with puffing intensity between the concentrations of acrylamide, butyraldehyde and phenol in THS 2.2 aerosol. With progressing puffing regime intensity, the generation and the transfer of aerosol in THS 2.2 strongly contrasted with the evolution of cigarette mainstream smoke. Since the yield for some HPHCs increased with the level of occlusion of the $3 \mathrm{R} 4 \mathrm{~F}$ filter ventilation, the threshold limits of reduction were lower for some HPHCs when THS 2.2 was compared with 3R4F using 50\% occlusion of filter ventilation. These differences are reflected by the respective threshold limit values reported in Table 4 and Table 5.

\section{DISCUSSION}

\section{$3 R 4 F$ filter ventilation}

Testing 3R4F cigarettes with $50 \%$ occlusion of filter ventilation holes was performed to embrace a broader range of possible conditions and showed the pertinence of using puff volume for the normalization of yields, focusing not only on the THS 2.2 product, but also on the $3 \mathrm{R} 4 \mathrm{~F}$ cigarette. Interestingly, the results showed consistent overall reductions across all puffing intensities between the two different conditions of filter ventilation used for the $3 \mathrm{R} 4 \mathrm{~F}$ cigarette. However, in the scope of the assessment for THS 2.2 robustness, the shift in relative reductions caused by the change of 3R4F filter ventilation for some individual constituents presented less interest than the overall influence of puffing intensity. Therefore, unless stated otherwise, the following discussion has focused upon reductions calculated using HPHC concentrations for 3R4F cigarette mainstream smoke generated with $100 \%$ occlusion of filter ventilation. This is also consistent with the requirements of the Health Canada Intense (HCI) machine-smoking regime of the Health Canada Tobacco Reporting Regulation (22) that was recommended by Public Health authorities, including the World Health Organization (WHO) (23).

\section{Robustness of average reduction}

Using the Health Canada Intense regime, and considering 49 constituents, the average reduction for puff volumeadjusted HPHC concentrations in THS 2.2 aerosol compared to 3R4F cigarette smoke was $93.6 \%(88.7 \%$ using nicotine-adjusted values). This is in line with published results (8) where the majority of HPHCs measured in THS 2.2 aerosol were reduced by more than $90 \%$. When more intense machine-smoking regimes were applied, average reductions based upon puff volumeadjusted concentrations for THS 2.2 were in the range from $94.2 \%$ to $95.9 \%$ (88.4\% to $89.3 \%$ using nicotine-adjusted values), irrespective of the smoking regime applied for the $3 \mathrm{R} 4 \mathrm{~F}$ reference cigarette, demonstrating a very robust performance for overall HPHC reduction.

\section{Individual HPHC reductions, robustness and precursors}

Each puff taken from a cigarette burns a new portion of the tobacco rod as opposed to the different zones of the unique portion of tobacco that are progressively heated and repeatedly used over puffs in THS 2.2. Therefore, depending on the nature of precursors and the release mechanisms of individual HPHCs, different levels of 
Table 3. HPHCs categorized by threshold limit of robust reduction over all regimes (THS $2.2 \mathrm{vs}$. $3 \mathrm{R} 4 \mathrm{~F} 100 \%$ occlusion of filter ventilation).

\begin{tabular}{|c|c|c|}
\hline Compounds & $\mathrm{n}$ & Limit \\
\hline $\begin{array}{l}\text { 1,3-Butadiene, 1-aminonaphthalene, 2-aminonaphthalene, 3-aminobiphenyl, 4-aminobiphenyl, benzene, Cd, } \\
\text { isoprene, o-toluidine }\end{array}$ & 9 & $\geq 99$ \\
\hline $\begin{array}{l}\text { Acrylonitrile, } \mathrm{CO} \text {, ethylene oxide, } \mathrm{HCN}, m \text {-cresol, } \mathrm{NNK}, \mathrm{NNN}, \mathrm{NO}, \mathrm{NO}_{x}, p \text {-cresol, quinoline, resorcinol, styrene, } \\
\text { toluene, vinyl chloride }\end{array}$ & 15 & $\geq 95$ \\
\hline Acetone, acrolein, benzo[a]anthracene, benzo[a]pyrene, crotonaldehyde, hydroquinone, MEK, NAT, o-cresol & 9 & $\geq 90$ \\
\hline $\mathrm{NAB}, \mathrm{Pb}$, pyrene & 3 & $\geq 85$ \\
\hline As, catechol & 2 & $\geq 80$ \\
\hline Formaldehyde, propionaldehyde, pyridine, & 3 & $\geq 75$ \\
\hline Acetaldehyde, dibenz[a, $h]$ anthracene, propylene oxide & 3 & $\geq 70$ \\
\hline Acetamide & 2 & $\geq 65$ \\
\hline Acrylamide & 1 & $\geq 60$ \\
\hline Ammonia, phenol & 2 & $\geq 55$ \\
\hline- & 0 & $\geq 50$ \\
\hline Butyraldehyde, $\mathrm{Hg}$ & 2 & $<50$ \\
\hline
\end{tabular}

Table 4. HPHCs categorized by threshold limit of robust reduction under $\mathrm{HCl}$ and more intense regimes and excluding ISO regime (THS 2.2 vs. 3R4F $100 \%$ occlusion of filter ventilation).

\begin{tabular}{|c|c|c|}
\hline Compounds & $\mathrm{n}$ & Limit \\
\hline $\begin{array}{l}\text { 1-Aminonaphthalene, 2-aminonaphthalene, 3-aminobiphenyl, 4-aminobiphenyl, 1,3-butadiene, acrylonitrile, } \\
\text { benzene, Cd, HCN, isoprene, o-toluidine }\end{array}$ & 11 & $\geq 99$ \\
\hline $\begin{array}{l}\text { Benzo[a]pyrene, } \mathrm{CO} \text {, ethylene oxide, } m \text {-cresol MEK, NAT, NNK, NNN, NO, } \mathrm{NO}_{x}, \mathrm{~Pb}, p \text {-cresol, quinoline, } \\
\text { resorcinol, styrene, toluene, vinyl chloride }\end{array}$ & 17 & $\geq 95$ \\
\hline Acetone, acrolein, As, benzo[a]anthracene, crotonaldehyde, hydroquinone, NAB, o-cresol, pyrene & 9 & $\geq 90$ \\
\hline Acetaldehyde, dibenz $[a, h]$ anthracene, formaldehyde, propionaldehyde, propylene oxide & 5 & $\geq 85$ \\
\hline Catechol & 1 & $\geq 80$ \\
\hline Butyraldehyde, pyridine & 2 & $\geq 75$ \\
\hline- & 0 & $\geq 70$ \\
\hline Acetamide & 1 & $\geq 65$ \\
\hline Acrylamide & 1 & $\geq 60$ \\
\hline Ammonia, phenol & 2 & $\geq 55$ \\
\hline $\mathrm{Hg}$ & 1 & $\geq 50$ \\
\hline
\end{tabular}

Table 5. HPHCs categorized by threshold limit of robust reduction under $\mathrm{HCl}$ and more intense regimes and excluding ISO regime (THS 2.2 vs. 3R4F $50 \%$ occlusion of filter ventilation).

\begin{tabular}{|c|c|c|}
\hline Compounds & $\mathrm{n}$ & Limit \\
\hline $\begin{array}{l}\text { 1-Aminonaphthalene, 2-aminonaphthalene, 3-aminobiphenyl, 4-aminobiphenyl, 1,3-butadiene, acrylonitrile, } \\
\text { benzene, } \mathrm{Cd}, \mathrm{HCN} \text {, isoprene }\end{array}$ & 10 & $\geq 99$ \\
\hline $\begin{array}{l}\mathrm{CO} \text {, ethylene oxide, } m \text {-cresol, } \mathrm{NNK}, \mathrm{NNN}, \mathrm{NO}, \mathrm{NO}_{x} \text {, o-toluidine, } p \text {-cresol, vinyl chloride, quinoline, resorcinol, } \\
\text { styrene, toluene }\end{array}$ & 14 & $\geq 95$ \\
\hline Acetone, acrolein, benzo[a]anthracene, benzo[a]pyrene, hydroquinone, MEK, NAB, NAT, o-cresol, Pb, pyrene & 11 & $\geq 90$ \\
\hline Crotonaldehyde, propionaldehyde & 2 & $\geq 85$ \\
\hline Acetaldehyde, As, catechol, dibenz $[a, h]$ anthracene, formaldehyde & 5 & $\geq 80$ \\
\hline- & 0 & $\geq 75$ \\
\hline Butyraldehyde, pyridine & 2 & $\geq 70$ \\
\hline- & 0 & $\geq 65$ \\
\hline Acetamide, propylene oxide & 2 & $\geq 60$ \\
\hline Acrylamide, phenol & 2 & $\geq 55$ \\
\hline Ammonia & 1 & $\geq 50$ \\
\hline $\mathrm{Hg}$ & 1 & $<50$ \\
\hline
\end{tabular}

Abbreviations: As, arsenic; $\mathrm{CO}$, carbon monoxide; $\mathrm{HCN}$, hydrogen cyanide; $\mathrm{Hg}$, mercury; MEK, methyl ethyl ketone; NAB, $N$-nitrosoanabasine; $\mathrm{NAT}, \mathrm{N}$-nitrosoanatabine; NNK, 4-( $\mathrm{N}$-nitrosomethylamino)-1-(3-pyridyl)-1-butanone; $\mathrm{NNN}, \mathrm{N}$-nitrosonornicotine; $\mathrm{NO}$, nitrogen oxide; $\mathrm{NO}_{\mathrm{x}}$, nitrogen oxides; $\mathrm{Pb}$, lead 


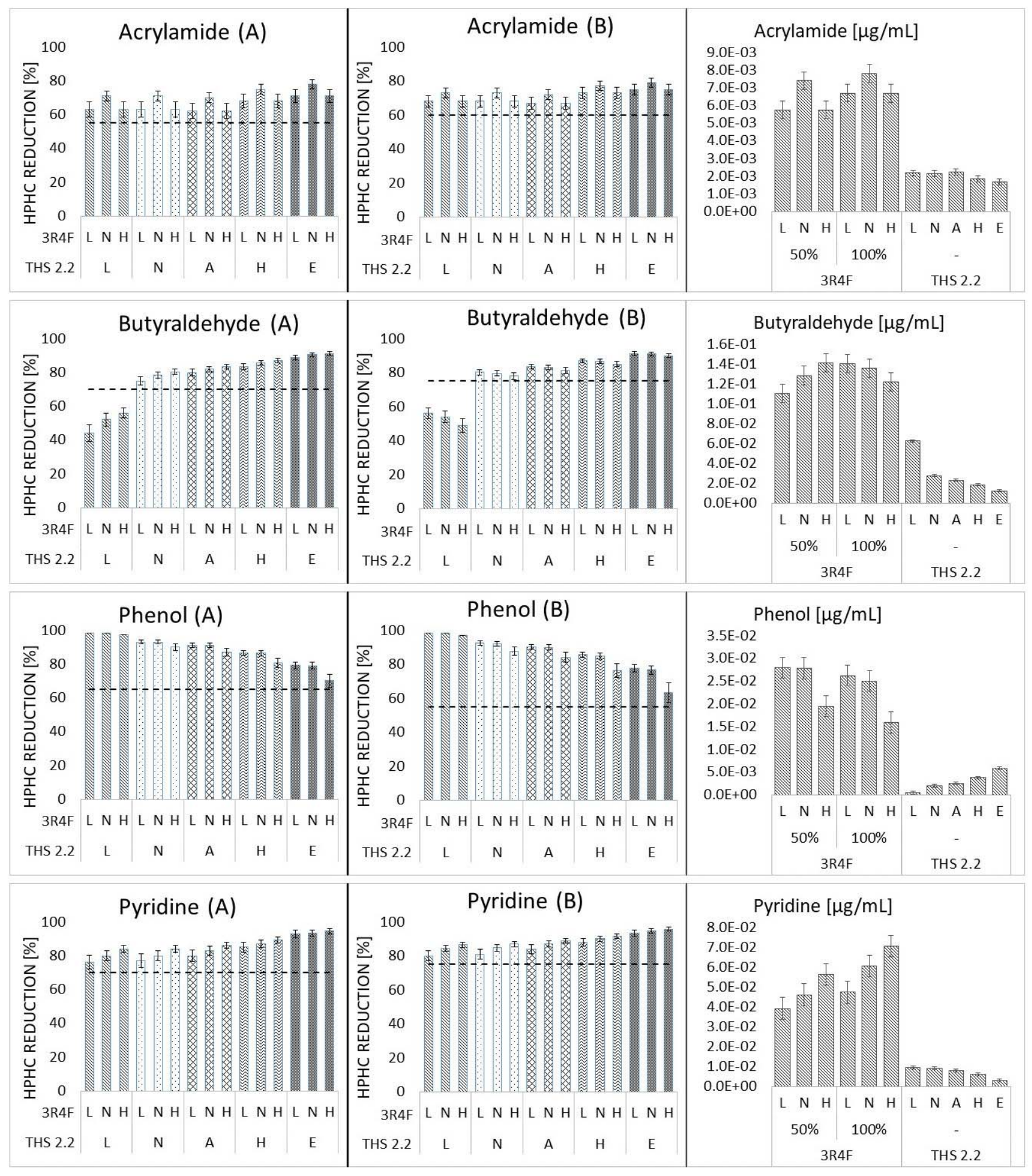

Figure 3. HPHC reduction with 0.95 confidence interval (error bars) calculated for $3 R 4 \mathrm{~F}$ filter ventilation occlusion of $50 \%$ (A) and $100 \%(B)$. The dashed lines indicate the lower limit of reduction defined for THS 2.2 under $\mathrm{HCl}$ and more intense regimes. Charts on the right hand side are individual means of aerosol/smoke concentrations determined for each product and condition. The respective puffing conditions identified by $\mathrm{A}, \mathrm{E}, \mathrm{H}, \mathrm{L}$ and $\mathrm{N}$ are described in Table 1 and Table 2.

reductions are expected between individual HPHCs and regimes.

Metals and metalloids are absorbed in growing tobacco leaves at harvesting point (24) and some of them can be transferred in THS 2.2 aerosol. The threshold limit of robust reduction of $50 \%$ observed for mercury contrasted with arsenic, lead and cadmium having higher limits of
$90 \%, 95 \%$ and $99 \%$, respectively. The fact that mercury can distill out of tobacco at a relatively low temperature (25-26) is a possible cause of this difference.

Heating a nitrogen-rich biomass such as tobacco produces ammonia (25). Acrylamide can be formed from asparagine and reducing sugars through a Maillard-type reaction occurring between $120^{\circ} \mathrm{C}$ and $200^{\circ} \mathrm{C} \mathrm{(27-30).} \mathrm{Acetamide}$ 
can be formed by the pyrolysis of Amadori compounds, which are reaction products needing amino acids and sugars, and by the decomposition of ammonium acetate at around $250{ }^{\circ} \mathrm{C} \mathrm{(31).} \mathrm{Pyridine} \mathrm{can} \mathrm{be} \mathrm{formed} \mathrm{below} 300^{\circ} \mathrm{C}$ through a classic Maillard reaction (32). These nitrogencontaining products are formed and distill out of tobacco at a low temperature. It was therefore unsurprising to observe threshold limits of robust reduction in the range of 55-75\%. In contrast, the five investigated aromatic amines demonstrated a limit of $99 \%$, which denoted consistently low levels of generation at THS 2.2 operating temperatures. Quinic acid and quinic acid derivatives, that are building blocks in the natural biosynthesis of lignin, were identified as important precursors of hydroquinone, catechol, and phenol which can be formed below $350{ }^{\circ} \mathrm{C}$ (33). Phenol concentration in THS 2.2 aerosol increased simultaneously with puffing regime intensity, which resulted in a diminution of phenol reduction from $92.2 \pm 1.4 \%$ (HCI) to $63.2 \pm 5.8 \%$ (extreme regime) for the lowest performance and was reflected by a threshold limit of reduction of $55 \%$. This was possibly caused by the progressive saturation and the subsequent elution of phenol adsorbed on tobacco and other filters (34-35).

PAHs can enter tobacco leaves during curing if the tobacco is exposed to exhaust gases from wood, or other organic fuel, heat sources (36). When studying the aerosol content of benzo $[a]$ pyrene, benz $[a]$ anthracene and pyrene in aerosols produced by different tobacco blends in the THS 2.2 (see Supplementary information Table S 9), it was observed that the yields of these PAHs were linked to the tobacco composition of the different blends (37). The results presented in Supplementary information Table S 9 show that the transfer of benzo $[a]$ pyrene, benz $[a]$ anthracene and pyrene in THS 2.2 was proportional to the PAH content of the tobacco materials of the sticks, and very good correlations $(r>0.99)$ were observed for these three PAHs when comparing yields in tobacco and in aerosol produced under HCI. Considering more intense regimes and supported by a threshold limit of robust reduction of $90 \%$ for benz $[a]$ anthracene and pyrene and $95 \%$ for benzo $[a]$ pyrene, the results showed that the PAHs detected in the aerosols of the THS 2.2 are most likely due to stripping caused by the gas stream and not to pyrosynthetic formation occurring during the THS 2.2 heating process.

The largest quantities of TSNAs are formed during tobacco curing and processing (38-40) and additional amounts could be formed during smoking. TSNAs distillate out of tobacco at low temperature, nevertheless heating instead of burning tobacco in THS 2.2 results in a 2-3 times lower transfer of TSNAs when compared with the transfer rates found for cigarettes (41). Under HCI and more intense regimes, the limit of threshold reduction was $95 \%$ for NNN, NNK and NAT whereas the limit was $90 \%$ for NAB; this difference could be attributed to individual transfer rates of TSNAs (41-42).

Carbon monoxide, $\mathrm{HCN}$, nitrogen oxides and volatile organic compounds such as 1,3-butadiene, acrylonitrile, benzene, styrene and toluene are generated only at low levels in THS 2.2 aerosol during thermochemical degradation of the tobacco material and have demonstrated threshold limits of a robust reduction of $90 \%$ or higher. A slightly lower limit of $85 \%$ was observed for propylene oxide. The dehydration of propylene glycol used as humectant or for the application of flavors to tobacco is a possible source of propylene oxide in mainstream cigarette smoke (43-44), however the absence of propylene glycol in the recipe of the $3 \mathrm{R} 4 \mathrm{~F}$ cigarette (45) suggests other possible precursors may have a role in the formation of propylene oxide. Amongst compounds with less clear sources, the limit was $95 \%$ for both vinyl chloride and ethylene oxide.

The threshold limits of robust reduction were in the range of $75-95 \%$ for all carbonyls investigated under HCI and more intense regimes. The lowest performance of reduction was for butyraldehyde and could denote a low temperature of formation. The threshold limit of robust reduction of $75 \%$ is in good agreement with values reported in the literature for tests conducted under HCI regimes, e.g., $71.13 \%$ (46) and 75.6\% (47). Like most other carbonyls, butyraldehyde content in THS 2.2 aerosol steadily dropped with increasing puffing intensity, therefore the highest concentrations were observed in THS 2.2 aerosol generated with the lowest puffing intensities. For butyraldehyde under ISO conditions, a relatively low reduction of $41.92 \%$ was published (46). This is consistent with the reductions of $56 \pm 3 \%$ and $43 \pm 5 \%$ obtained in the present study with the same smoking-machine parameters, taking also into account a difference in the occlusion levels used for 3R4F filter ventilation, respectively $100 \%$ and $50 \%$.

\section{CONCLUSIONS}

The present study has demonstrated the robustness of THS 2.2, a heat-not-burn tobacco product, in its ability to reduce the levels of HPHCs in the aerosol produced using a broad range of puffing conditions, particularly for HCI and more intense regimes. The transformation of HPHCs yields into concentrations in mass normalized per total puff volume is a recent approach, appropriate for the crosscomparison of a large range of puffing conditions. Moreover, this work has substantially contributed to paving the road for the assessment of current and future products, where the application of current standard machine-smoking regimes would present limitations considering the constant evolution of products.

Machine-smoking testing is useful in characterizing tobacco product emissions for design and regulatory purposes. The demonstration of product robustness substantiates the evidence package provided in the due diligence assessment of the THS 2.2 product. In this context, the study demonstrated that, overall, the concentrations of investigated HPHCs were reduced by more than $90 \%$ under HCI and more intense regimes, and this was established with a conservative approach including a broad range of conditions for the generation of 3R4F cigarette mainstream smoke used as reference.

The concept of threshold limits applied for robust concentration reduction was introduced to categorize each HPHC investigated in THS 2.2 as a function of its demonstrated level of robust reduction. Based on the outcome of this study, the puff volume normalization approach is considered appropriate for the machine-smoking evaluation of the robustness for HPHC reduction in future assessments 
of similar products, where the nicotine-adjusted yield approach would not be applicable. For the assessment of the robustness under HCI and more intense regimes, which exclude therefore the ISO regime, the use of the $3 \mathrm{R} 4 \mathrm{~F}$ reference cigarette with $100 \%$ blocked filter ventilation is recommended. Under these specific conditions, THS 2.2 showed robust performance in the reduction of the levels of HPHCs and, regardless of the puffing regime, could remain within the respective limits identified by the present study for each relevant compound (c.f. Table 4).

\section{ASSOCIATED CONTENT}

The Supporting Information is available free of charge on the Publications website:

- Description of supplementary tables S1-S9 (PDF)

- Supplementary Information Table S1 (PDF)

- Supplementary Information Tables S2-S9 (XLXS)

\section{AUTHORS INFORMATION}

The research described in this article was funded by Philip Morris Products S.A. All authors are employees of Philip Morris Products S.A.

\section{REFERENCES}

1. Djordjevic, M.V., S.D. Stellman, and E. Zang: Doses of Nicotine and Lung Carcinogens Delivered to Cigarette Smokers; J. Nat. Cancer Inst. 92 (2000) 106-111. DOI: 10.1093/jnci/92.2.106

2. World Health Organization (WHO), Study Group on Tobacco Product Regulation: Report on the Scientific Basis of Tobacco Product Regulations: Fifth Report of a WHO Study Group; WHO Technical Report Series, No. 989: 2015. Available at: https://escholarship.org/ content/qt81m4m677/qt81m4m677.pdf(accessed May 25, 2020).

3. Dawkins, L.E., C.F. Kimber, M. Doig, C. Feyerabend, and O. Corcoran: Self-Titration by Experienced E-Cigarette Users: Blood Nicotine Delivery and Subjective Effects; Psychopharmacology (Berl.) 233 (2016) 2933-2941. DOI: 10.1007/s00213-016-4338-2

4. Hiler, M., A. Breland, T. Spindle, S. Maloney, T. Lipato, N. Karaoghlanian, A. Shihadeh, A. Lopez, C. Ramôa, and T. Eissenberg: Electronic Cigarette User Plasma Nicotine Concentration, Puff Topography, Heart Rate, and Subjective Effects: Influence of Liquid Nicotine Concentration and User Experience; Exp. Clin. Psychopharmacol. 25 (2017) 380-392.

DOI: $10.1037 /$ pha0000140

5. Belushkin, M., M. Esposito, G. Jaccard, C. Jeannet, A. Korneliou, and D.T. Djoko: Role of Testing Standards in Smoke-Free Product Assessments; Regul. Toxicol. Pharmacol. 98 (2018) 1-8. DOI: 10.1016/j.yrtph.2018.06.021

6. Counts, M.E., M.J. Morton, S.W. Laffoon, R.H. Cox, and P.J. Lipowicz: Smoke Composition and Predicting Relationships for International Commercial Cigarettes
Smoked with Three Machine-Smoking Conditions; Regul. Toxicol. Pharmacol. 41 (2005) 185-227. DOI: 10.1016/j.yrtph.2004.12.002

7. Poget, L., P. Campelos, C. Jeannet, and S. Maeder: Development of Models for the Estimation of Mouth Level Exposure to Aerosol Constituents from a Heat-Not-Burn Tobacco Product Using Mouthpiece Analysis; Beitr. Tabakforsch. Int. 27 (2017) 42-64.

DOI: $10.1515 /$ cttr-2017-0005

8. Smith, M.R., B. Clark, F. Lüdicke, J.-P. Schaller, P. Vanscheeuwijck, J. Hoeng, and M.C. Peitsch: Evaluation of the Tobacco Heating System 2.2. Part 1: Description of the System and the Scientific Assessment Program; Regul. Toxicol. Pharmacol. 81 Suppl. 2 (2016) S17-S26. DOI: 10.1016/j.yrtph.2016.07.006

9. Schaller, J.-P., D. Keller, L. Poget, P. Pratte, E. Kaelin, D. McHugh, G. Cudazzo, D. Smart, A.R. Tricker, L. Gautier, M. Yerly, R. Reis Pires, S. Le Bouhellec, D. Ghosh, I. Hofer, E. Garcia, P. Vanscheeuwijck, and S. Maeder: Evaluation of the Tobacco Heating System 2.2. Part 2: Chemical Composition, Genotoxicity, Cytotoxicity, and Physical Properties of the Aerosol; Regul. Toxicol. Pharmacol. 81 (2016) S27-S47.

DOI: $10.1016 /$ j.yrtph.2016.10.001

10. Cooperation Centre for Scientific Research Relative to Tobacco (CORESTA): CORESTA Recommended Method No 80 - Use of the Part-Filter Method for the Estimation of Smokers' Exposure to Nicotine and Nicotine-Free Dry Particulate Matter, 2016. Available at: https://www.coresta.org/sites/default/files/technical_ documents/main/CRM_80.pdf.

11. Zenzen, V., J. Diekmann, B. Gerstenberg, S. Weber, S. Wittke, and M.K. Schorp: Reduced Exposure Evaluation of an Electrically Heated Cigarette Smoking System. Part 2: Smoke Chemistry and in vitro Toxicological Evaluation Using Smoking Regimens Reflecting Human Puffing Behavior; Regul. Toxicol. Pharmacol. 64 (2012) S11-S34. DOI: 10.1016/j.yrtph.2012.08.004

12. International Organization for Standardization (ISO): ISO/IEC 17025:2005: General Requirements for the Competence of Testing and Calibration Laboratories; ISO, Geneva, Switzerland, 2005.

13. Government of Canada, Minister of Justice: Canadian Tobacco Reporting Regulations: Tobacco Reporting Regulations: 2000-07-19 Canada Gazette Part II, Vol. 134, No. 15 Part 3: Emissions from Designated Tobacco Products.

Test method numbers refer to Health Canada methodologies which have been posted by Health Canada on the internet. Available at: http://www.hc-sc.gc.ca/hl-vs/ tobac-tabac/legislation/reg/indust/index_e.html

14. International Organization for Standardization (ISO): ISO 3402:1999: Tobacco and Tobacco Products Atmosphere for Conditioning and Testing; ISO, Geneva, Switzerland, 2015.

15. Gelman, A., J.B. Carlin, H.S. Stern, D.B. Dunson, A. Vehtari, and D.B. Rubin: Bayesian Data Analysis, $3^{\text {rd }}$ edition; ISBN: 978-1-4398-4095-5, CRC Press, Boca Raton, FL, USA, 2013.

16. Kruschke, J.: Doing Bayesian Data Analysis: A Tutorial with R, JAGS, and Stan, $2^{\text {nd }}$ edition; ISBN: 978-0-12405888-0, Academic Press, London, UK, 2014. 
17. Robert, C.P. and G. Casella: Introducing Monte Carlo Methods with R, Springer, New York, NY, USA, 2010. DOI 10.1007/978-1-4419-1576-4

18. Littell, R.C., G.A. Milliken, W.W. Stroup, R.D. Wolfinger, and O. Schabenberger: SAS ${ }^{\circledR}$ for Mixed Models; ISBN: 978-159047-500-3, SAS Institute, Cary, NC, USA, 2006.

19. West, B.T., K.B. Welch, and A.T. Galecki: Linear Mixed Models: A Practical Guide Using Statistical Software, $2^{\text {nd }}$ edition; ISBN: 978-1-4665-6099-4, CRC Press, Boca Raton, FL, USA, 2014.

20. Haziza, C., G. de La Bourdonnaye, S. Merlet, M. Benzimra, J. Ancerewicz, A. Donelli, G. Baker, P. Picavet, and F. Lüdicke: Assessment of the Reduction in Levels of Exposure to Harmful and Potentially Harmful Constituents in Japanese Subjects Using a Novel Tobacco Heating System Compared with Conventional Cigarettes and Smoking Abstinence: A Randomized Controlled Study in Confinement; Regul. Toxicol. Pharmacol. 81 (2016) 489-499.

DOI: 10.1016/j.yrtph.2016.09.014

21. Haziza, C., G. de La Bourdonnaye, D. Skiada, J. Ancerewicz, G. Baker, P. Picavet, and F. Lüdicke: Evaluation of the Tobacco Heating System 2.2. Part 8: 5-Day Randomized Reduced Exposure Clinical Study in Poland; Regul. Toxicol. Pharmacol. 81 (2016) S139-S150. DOI: 10.1016/j.yrtph.2016.11.003

22. Heath Canada: Official Method T-115: Determination of "Tar", Nicotine and Carbon Monoxide in Mainstream Tobacco, Ottawa, Canada, 1999, pp. 1-7.

23. World Health Organization (WHO), Tobacco Laboratory Network: Standard Operating Procedure for Intense Smoking of Cigarettes. WHO (TobLabNet) Official Method SOP 1; ISBN: 978-92-4-150389-1, WHO, Geneva, Switzerland, 2012.

24. Campbell, R.C.J.: Speciation of Metals and Metalloids in Tobacco and Tobacco Smoke: Implications for Health and Regulation; Thesis, University of St Andrews, 2014. Available at: https://research-repository.standrews.ac.uk/bitstream/handle/10023/5728/Robert CampbellPhDThesis.pdf;sequence $=3$ (accessed May 25, 2020).

25. McDaniel, R.L., K.M. Torrence, D.A. Self and M.J. Chang: Determination of Mercury in Mainstream Cigarette Smoke by Conventional and Amalgamation Cold Vapor Atomic Absorption Spectrometry; Beitr. Tabakforsch. Int. 19 (2001) 267-276.

DOI: $10.2478 /$ cttr-2013-0713

26. Pappas, R. S.: Toxic Elements in Tobacco and in Cigarette Smoke: Inflammation and Sensitization; Metallomics 3 (2011): 1181-1198.

DOI: $10.1039 / \mathrm{c} 1 \mathrm{mt} 00066 \mathrm{~g}$

27. Becalski, A., B. Brady, S. Feng, B.R. Gauthier and T. Zhao: Formation of Acrylamide at Temperatures Lower than $100{ }^{\circ} \mathrm{C}$ : The Case of Prunes and a Model Study; Food Addit. Contam. 28 (2011) 726-730. DOI: $10.1080 / 19440049.2010 .535217$

28. Becalski, A., B.P.-Y. Lau, D. Lewis and S.W. Seaman: Acrylamide in Foods: Occurrence, Sources, and Modeling; J. Agric. Food Chem. 51 (2003) 802-808. DOI: $10.1021 / \mathrm{jf0} 20889 \mathrm{y}$

29. Blank, I., F. Robert, T. Goldmann, P. Pollien, N. Varga,
S. Devaud, F. Saucy, T. Huynh-Ba and R.H. Stadler: Mechanisms of Acrylamide Formation; in: Chemistry and Safety of Acrylamide in Food, edited by M. Friedman and D. Mottram, ISBN: 0-387-23920-0, Springer US, Boston, MA, USA, 2005; pp 171-189.

DOI: $10.1007 / 0-387-24980-X \quad 14$

30. Stadler, R.H., I. Blank, N. Varga, F. Robert, J. Hau, P.A. Guy, M.-C. Robert and S. Riediker: Acrylamide from Maillard Reaction Products; Nature 419 (2002) 449-450. DOI: 10.1038/419449a

31. Moldoveanu, S.C.: Pyrolysis of Organic Molecules with Applications to Health and Environmental Issues; ISBN: 978-0-444-53113-1, Elsevier, Amsterdam, The Netherlands, 2009.

32. Baggenstoss, J., L. Poisson, R. Kaegi, R. Perren and F. Escher: Coffee Roasting and Aroma Formation: Application of Different Time-Temperature Conditions; J. Agric. Food Chem. 56 (2008) 5836-5846.

DOI: $10.1021 / \mathrm{jf} 800327 \mathrm{j}$

33. McGrath, T.E., A.P. Brown, N.K. Meruva and W.G. Chan: Phenolic Compound Formation from the Low Temperature Pyrolysis of Tobacco; J. Anal. Appl. Pyrol. 84 (2009) 170-178.

DOI: $10.1016 /$ j.jaap.2009.01.008

34. Jianhui, W., D. Wen, P. Bin, Z. Xiaobing, X. Fuwei, L. Huimin and Z. Kejun: Filtration and Retention Characteristics of Smoke Components in Filters; Beitr. Tabakforsch. Int. 26 (2014) 121-131. DOI: $10.2478 /$ cttr-2014-0015

35. Hoffmann, D. and E.L. Wynder: Filtration of Phenols from Cigarette Smoke; J. Nat. Cancer Inst. 30 (1963) 67-84. DOI: $10.1093 /$ jnci/30.1.67

36. Bentley, H. and J. Burgan: Polynuclear Hydrocarbons in Tobacco and Tobacco Smoke. Part II. The Origin of 3:4-Benzopyrene Found in Tobacco and Tobacco Smoke; Analyst 85 (1960) 723-727. DOI: $10.1039 / A N 9608500723$

37. Schaller, J.-P., J.P.M. Pijnenburg, A. Ajithkumar and A.R. Tricker: Evaluation of the Tobacco Heating System 2.2. Part 3: Influence of the Tobacco Blend on the Formation of Harmful and Potentially Harmful Constituents of the Tobacco Heating System 2.2 Aerosol; Regul. Toxicol. Pharmacol. 81 (2016) S48-S58.

DOI: 10.1016/j.yrtph.2016.10.016

38. Wiernik, A., A. Christakopoulos, L. Johansson and I. Wahlberg: Effect of Air-Curing on the Chemical Composition of Tobacco; Recent Adv. Tob. Sci. 21 (1995) 39-80.

39. Fisher, M.T., C.B. Bennett, A. Hayes, Y. Kargalioglu, B.L. Knox, D. Xu, R. Muhammad-Kah and C.L. Gaworski: Sources of and Technical Approaches for the Abatement of Tobacco Specific Nitrosamine Formation in Moist Smokeless Tobacco Products; Food Chem. Toxicol. 50 (2012) 942-948.

DOI: $10.1016 /$ j.fct.2011.11.035

40. Brunnemann, K.D. and D. Hoffmann: Analytical Studies on Tobacco-Specific $N$-Nitrosamines in Tobacco and Tobacco Smoke; Crit. Rev. Toxicol. 21 (1991) 235-240. DOI: 10.3109/10408449109017910

41. Jaccard, G., A. Kondylis, I. Gunduz, J. Pijnenburg and M. Belushkin: Investigation and Comparison of the Transfer of TSNA from Tobacco to Cigarette Main- 
stream Smoke and to the Aerosol of a Heated Tobacco Product, THS 2.2; Regul. Toxicol. Pharmacol. 97 (2018) 103-109. DOI: 10.1016/j.yrtph.2018.06.011

42. Bekki, K., Y. Inaba, S. Uchiyama and N. Kunugita: Comparison of Chemicals in Mainstream Smoke in Heat-Not-Burn Tobacco and Combustion Cigarettes; J, UOEH 39 (2017) 201-207. DOI: 10.7888/juoeh.39.201

43. Diekmann, J., M. Douda and K. Rustemeier: Rapid and Sensitive Method for the Determination of Propylene Oxide in Cigarette Mainstream Smoke by Gas Chromatography-Mass Spectrometry; J. Chromatogr. Sci. 44 (2006) 32-34. DOI: 10.1093/chromsci/44.1.32

44. Laino, T., C. Tuma, P. Moor, E. Martin, S. Stolz and A. Curioni: Mechanisms of Propylene Glycol and Triacetin Pyrolysis; J. Phys. Chem. A 116 (2012) 4602-4609. DOI: $10.1021 / j p 300997 d$

45. Jaccard, G., D.T. Djoko, A. Korneliou, R. Stabbert, M. Belushkin and M. Esposito: Mainstream Smoke Constituents and in vitro Toxicity Comparative Analysis of 3R4F and 1R6F Reference Cigarettes; Toxicol. Rep. 6 (2019) 222-231. DOI: 10.1016/j.toxrep.2019.02.009
46. Li, X., Y. Luo, X. Jiang, H. Zhang, F. Zhu, S. Hu, H. Hou, Q. Hu and Y. Pang: Chemical Analysis and Simulated Pyrolysis of Tobacco Heating System 2.2 Compared to Conventional Cigarettes; Nicotine Tob. Res. 21 (2019) 111-118. DOI: 10.1093/ntr/nty005

47. Jaccard, G., D.T. Djoko, O. Moennikes, C. Jeannet, A. Kondylis and M. Belushkin: Comparative Assessment of HPHC Yields in the Tobacco Heating System THS2.2 and Commercial Cigarettes; Regul. Toxicol. Pharmacol. 90 (2017) 1-8.

DOI: 10.1016/j.yrtph.2017.08.006

Corresponding author:

Laurent Poget

PMI R\&D

Philip Morris Products S.A.

Quai Jeanrenaud 5

CH-2000 Neuchâtel

Switzerland

E-mail:laurent.poget@pmi.com 


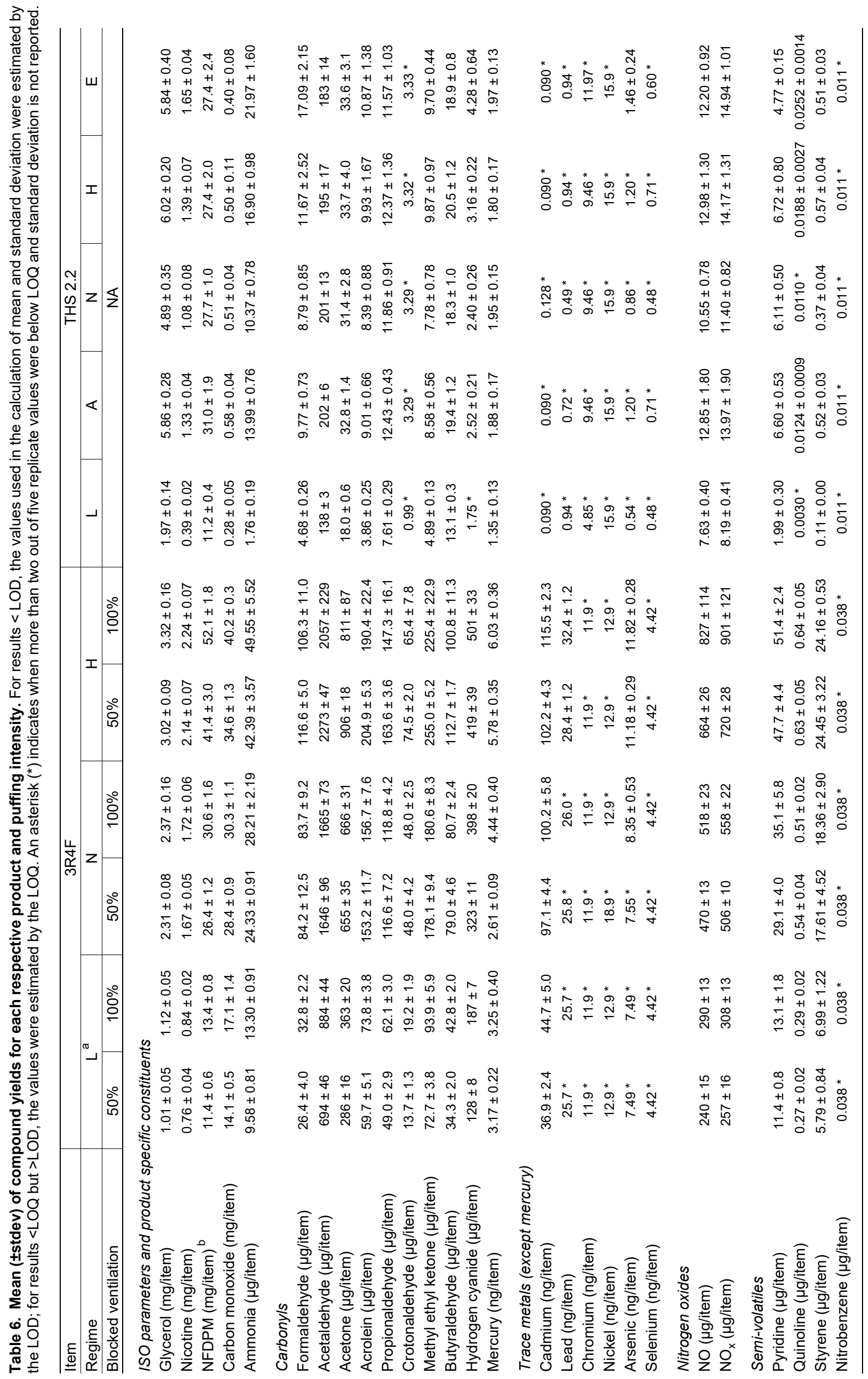




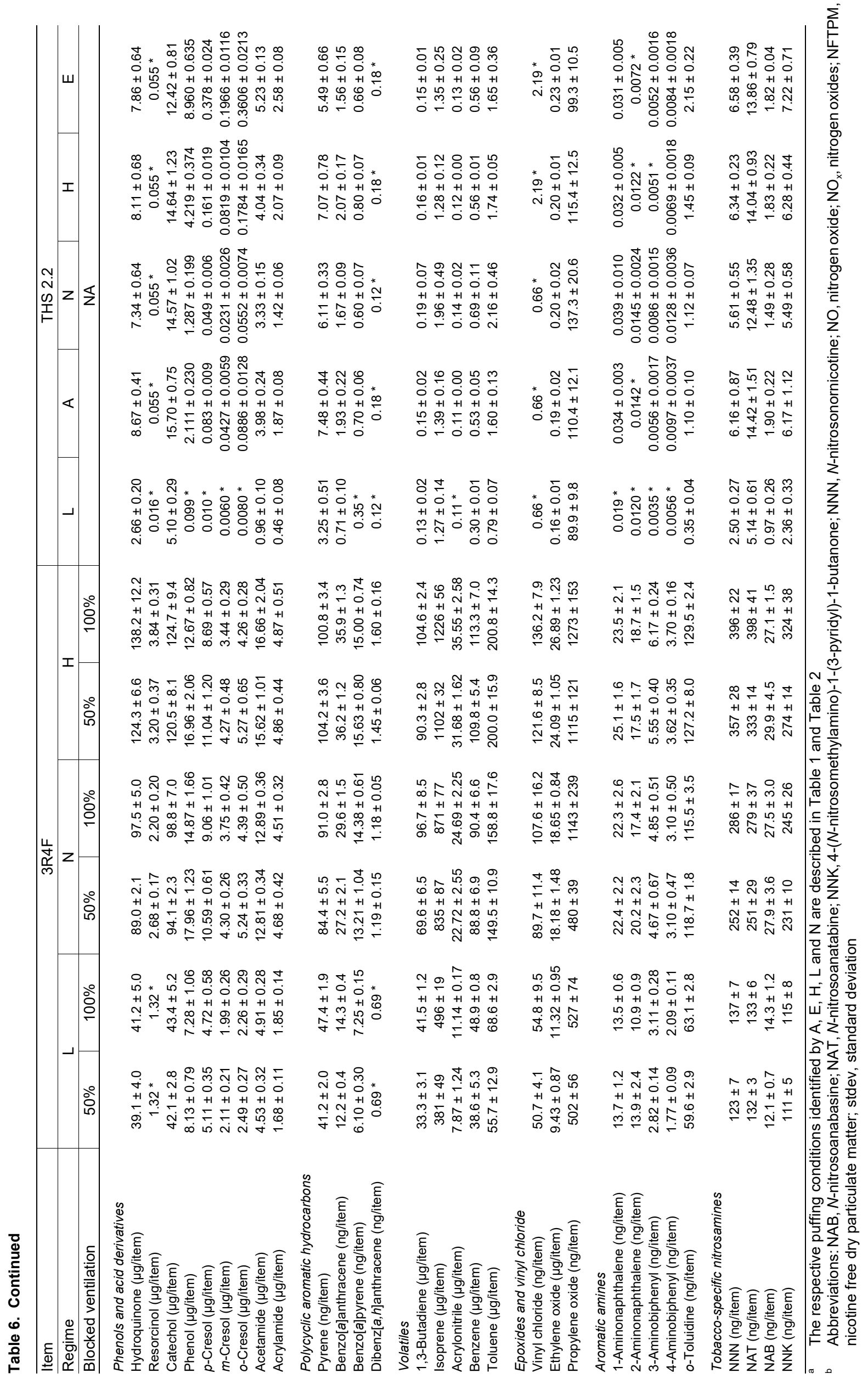




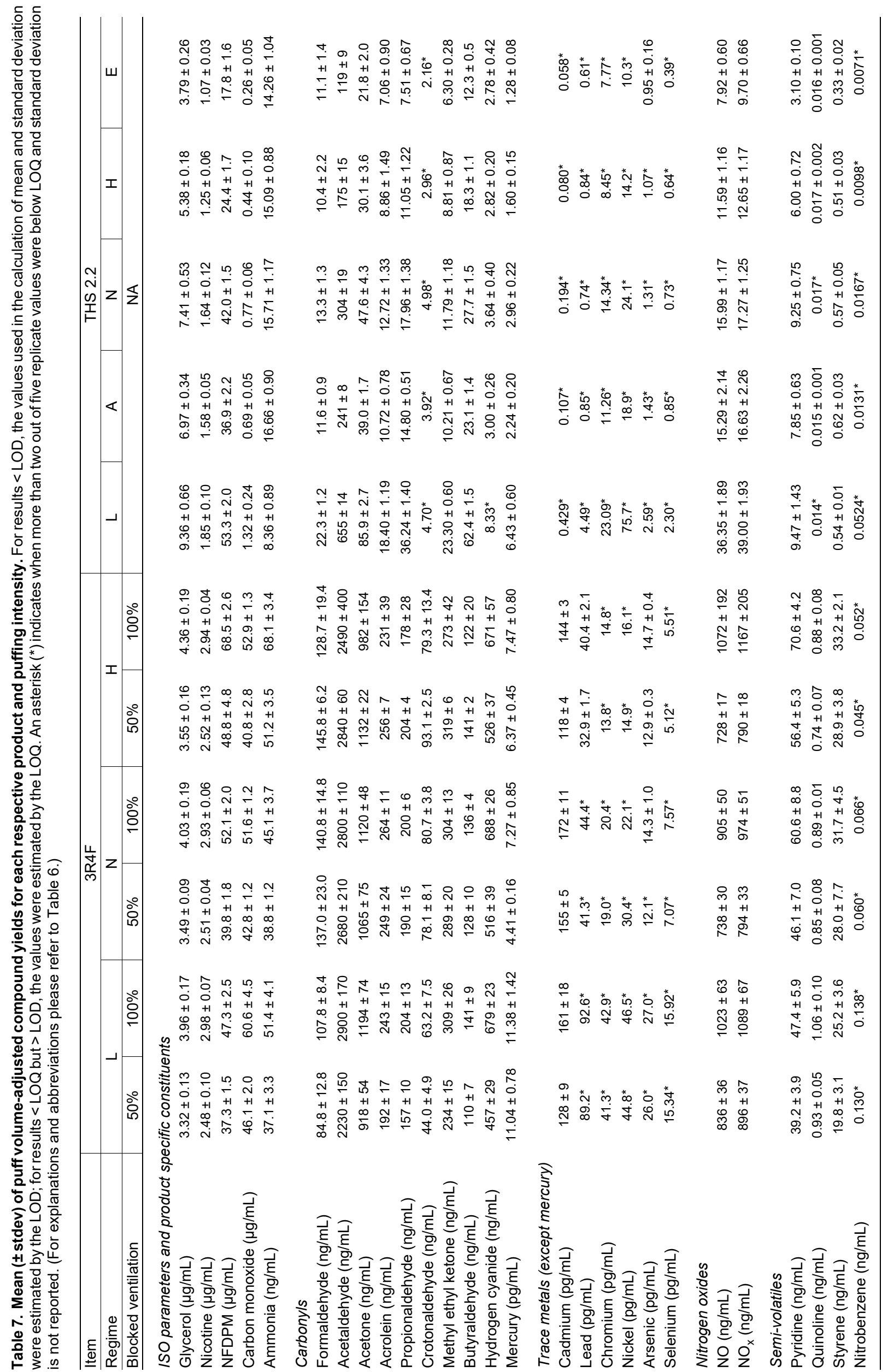




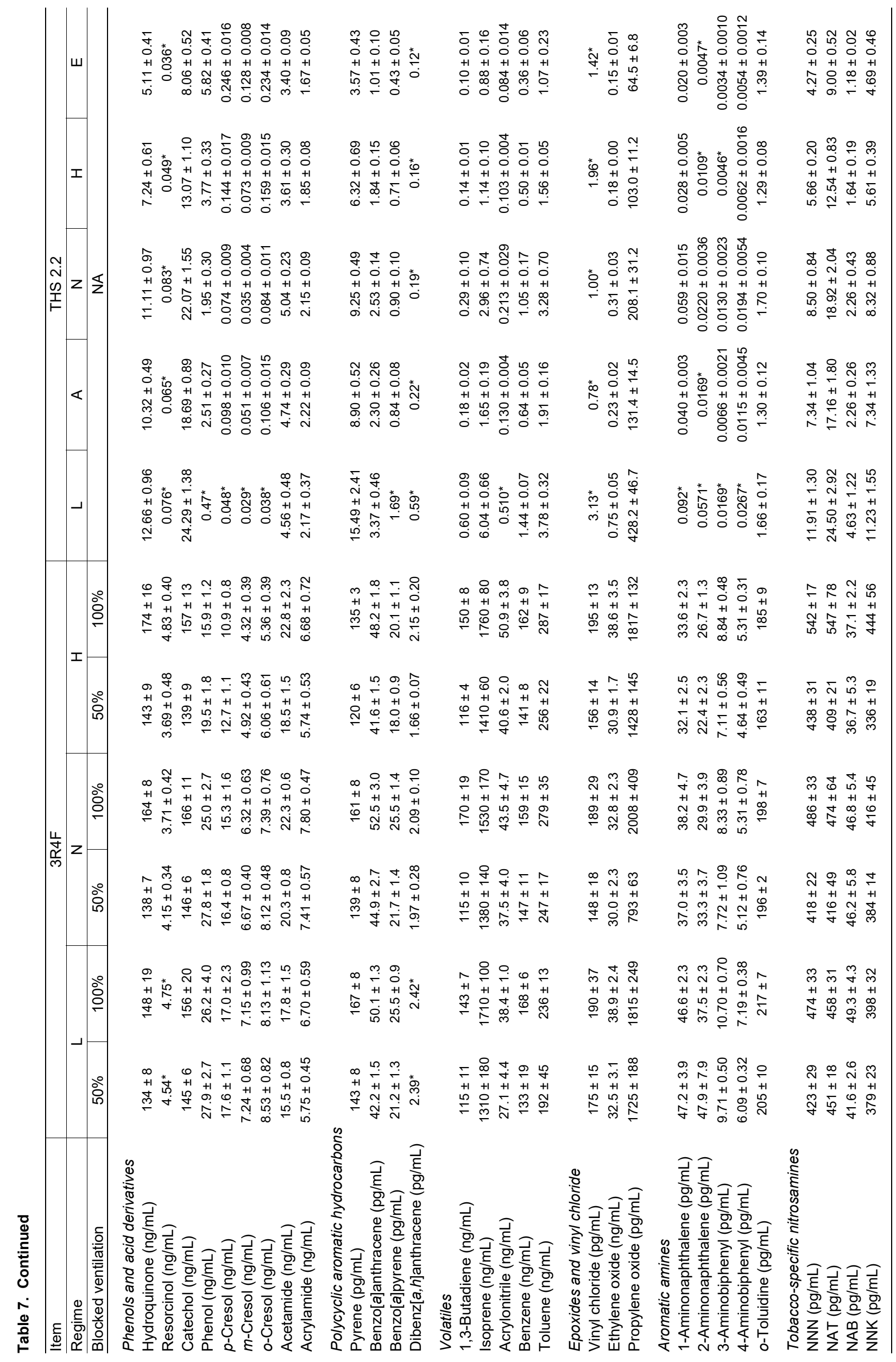




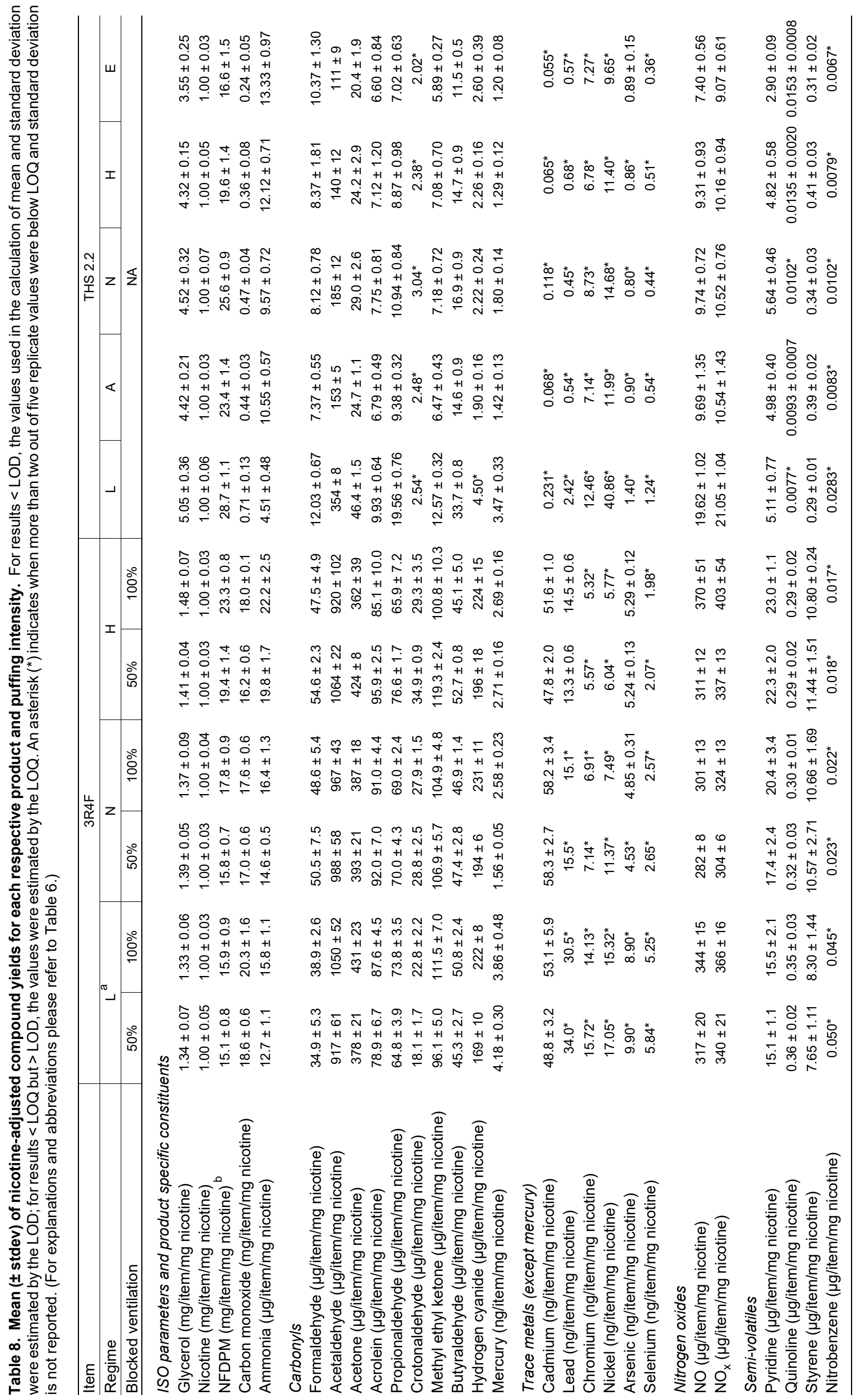




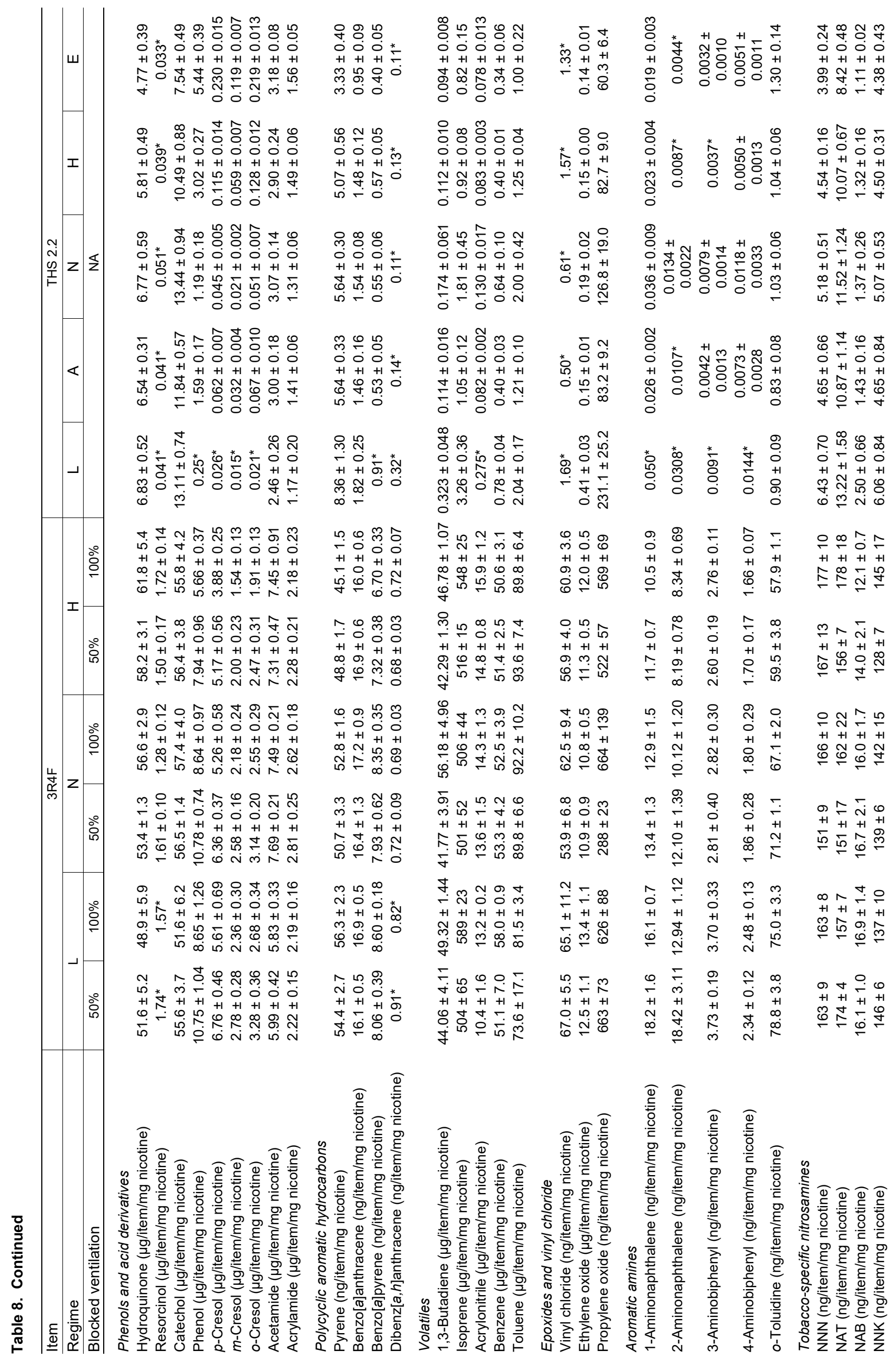

